\title{
Erratum to: Computer Simulation of the Mechanical Behaviour of Implanted Biodegradable Stents in a Remodelling Artery
}

\author{
ENDA L. BOLAND, ${ }^{1,2}$ JAMES A. GROGAN, ${ }^{1}$ CLAIRE CONWAY, ${ }^{1}$ \\ and PETER E. MCHUGH ${ }^{1}$ \\ 1.-Biomechanics Research Centre, Biomedical Engineering, College of Engineering and \\ Informatics, National University of Ireland Galway, Galway, Ireland. 2.-e-mail: e.boland1@ \\ nuigalway.ie
}

\section{Erratum to: JOM}

\section{DOI 10.1007/s11837-015-1761-5}

Due to an error during production, James A. Grogan's name appeared incorrectly in the original PDF version of this article. It has since been updated.

The online version of the original article can be found under doi:10.1007/ s11837-015-1761-5. 